\title{
Internal anal sphincter injury in the immediate postpartum period; Prevalence, risk factors and diagnostic methods in the Swedish perineal laceration registry
}

Sofia Pihl, Marie Blomberg and Eva Uustal Fornell

The self-archived postprint version of this journal article is available at Linköping University Institutional Repository (DiVA):

http://urn.kb.se/resolve?urn=urn:nbn:se:liu:diva-162583

N.B.: When citing this work, cite the original publication.

Pihl, S., Blomberg, M., Uustal Fornell, E., (2020), Internal anal sphincter injury in the immediate postpartum period; Prevalence, risk factors and diagnostic methods in the Swedish perineal laceration registry, European Journal of Obstetrics, Gynecology, and Reproductive Biology, 245, 1-6.

https://doi.org/10.1016/j.ejogrb.2019.11.030

Original publication available at:

https://doi.org/10.1016/j.ejogrb.2019.11.030

Copyright: Elsevier (12 months)

http://www.elsevier.com/

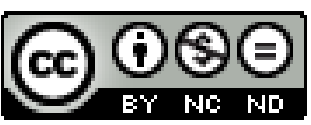


Internal anal sphincter injury in the immediate postpartum period; prevalence, risk factors and diagnostic methods in the Swedish Perineal Laceration

\section{Registry.}

Sofia PIHL MD ${ }^{1}$, Marie BLOMBERG, MD, $\mathrm{PhD}^{1}$, Eva UUSTAL, MD, $\mathrm{PhD}^{1}$

${ }^{1}$ Department of Obstetrics and Gynaecology, and Department of Clinical and Experimental Medicine, Linköping University, Linköping, Sweden

Funding: The study was made possible by unrestricted financial support from Region

Ostergotland, ALF grants, Region Ostergotland, Sweden and an unrestricted grant from TryggHansa.

Details of Ethics Approval: The Regional Ethical Review Board in Linköping has approved the study; (Ref 2016/144-31) 2016-04-20.

Corresponding author:

Dr. Sofia Pihl

Department of Obstetrics and Gynaecology

SE-581 85 Linköping Sweden

sofia.pihl@regionostergotland.se

Phone: +46709380729

Word count: 2498 


\title{
Internal anal sphincter injury in the immediate postpartum period; prevalence, risk factors and diagnostic methods in the Swedish Perineal Laceration
}

\author{
Registry.
}

Sofia PIHL MD ${ }^{1}$, Marie BLOMBERG, MD, $\mathrm{PhD}^{1}$, Eva UUSTAL, MD, $\mathrm{PhD}^{1}$

\begin{abstract}
:
Risk factors for obstetric external anal sphincter injury are well known. Maternal and obstetric risk factors for internal anal sphincter injury are not extensively studied.

The rationale of this study was to evaluate the proportion of internal anal sphincter injury in women with external anal sphincter injury, diagnosed immediately after delivery.

This study will assess whether there are additional risks for obstetric internal anal sphincter injury.

\section{Objectives}

The primary aim was to assess the proportion of internal anal sphincter injury immediately in women with an external sphincter injury and to evaluate maternal and obstetric risk factors for internal anal sphincter injury in women with an external anal sphincter injury only.

A secondary aim was to relate the diagnostic methods used for obstetric perineal lacerations to the presence of an internal anal sphincter injury.

\section{Study Design}

A registry study with data from the Swedish Perineal Laceration Registry 2014-2018.

From the registry, the maternal and obstetric characteristics of 3,333 primiparous women with isolated external $(\mathrm{N}=2,236)$ versus both external and internal $(\mathrm{N}=1,097)$ anal sphincter injuries were studied, as were the methods used for examining the obstetric anal sphincter injuries.

\section{Results}

In $32.9 \%(1,097 / 3,333)$ of primiparous women with an external anal sphincter injury, an internal anal sphincter injury was diagnosed immediately after delivery. A perineal palpatory thickness of 
less than 10 millimeters was a diagnostic sign for internal sphincter injury. Well-known risk factors associated with obstetric anal sphincter injuries could not be confirmed as independent risk factors for internal sphincter injury. When the infant is born with an arm beside the head, there is an almost two-fold increased risk for internal sphincter injury.

\title{
Conclusions
}

Our main finding is that $32.9 \%$ of women with external anal sphincter injury also have an internal anal sphincter injury. A palpable perineal thickness of less than $10 \mathrm{~mm}$, a degree 4-laceration and an infant born with a hand by the head increases the risk of internal sphincter injury and should be a clinical warning sign.

\section{Keywords}

Obstetric perineal laceration, internal anal sphincter injury.

\author{
Abbreviations \\ BMI - Body Mass Index \\ CI - Confidence Interval \\ EAS - External Anal Sphincter \\ IAS - Internal Anal Sphincter \\ ICD - International Classification of Disease \\ OASI - Obstetric Anal Sphincter Injuries \\ OR - Odds Ratio \\ PLR - Perineal Laceration Registry
}

\section{Introduction}

Obstetric perineal lacerations are diagnosed according to the WHO international classification of disease (ICD-10) $)^{(1)}$ from degree 1 to 4 depending on the tissues involved in the injury (fig 1 ). 
Involvement of the internal anal sphincter (IAS) has been separately diagnosed and classified as 3c (external and internal anal sphincter torn) or 4 (both anal sphincters and anal epithelium torn) since 2014 in Sweden. This classification was suggested by Uustal Fornell ${ }^{(2)}$ and later adapted by Sultan ${ }^{(3)}$.

Risk factors for external anal sphincter (EAS) injury are well known ${ }^{(4,5)}$. As to our knowledge, obstetric risk factors of IAS injury are not extensively studied earlier.

The IAS consists of a ring of smooth muscle, emanating from the intestinal wall and thickening into a sphincter in the proximal anal canal. It extends just cranially to the caudal part of the external anal sphincter to the dentate line.

The IAS contributes to $50-85 \%$ of the resting anal tone, the rest comes from the vascular anal cushions and the tonus of the external anal sphincter. IAS dysfunction can result in involuntary anal incontinence, impaired faecal sampling and faecal urgency ${ }^{(6)}$. The most common cause of low pressure of the IAS is an obstetrical injury ${ }^{(7)}$.

It has been shown that the IAS should be identified and sutured separately from the EAS for a better postoperative function $^{(8)}$. In follow-up studies with endoanal ultrasound, women with a persistent defect in the anal sphincters have more anal incontinence and a lower quality of life ${ }^{(9,10)}$, an association that is more explicit with an IAS defect than with an EAS defect ${ }^{(11)}$. The consistent conclusion of these studies is the presence of occult anal sphincter injuries ${ }^{(12,13)}$ and the importance of a correct perineal laceration diagnosis before primary suturing, to prevent long-term consequences ${ }^{(11,14)}$.

The potential relation between maternal and obstetric characteristics in women with an isolated EAS compared to women with both an EAS and an IAS has never been analyzed before.

Therefore, the primary aim of the present study was to assess the proportion of IAS injury immediately postpartum in women with an EAS injury and to evaluate maternal and obstetric risk 
factors for IAS injury compared to EAS injury only. The secondary aim was to relate the diagnostic methods of obstetric anal sphincter injury to the presence of an IAS injury.

\section{Materials and Methods}

In Sweden, the attending midwife establishes the degree of perineal laceration after delivery. This initial examination consists of an inspection and palpation of the perineal tissues. The distance between the bottom of the laceration and the anal canal can be palpated. If a more extensive perineal laceration or involvement of the anal sphincters is suspected, the obstetrician on call performs a more detailed examination to ascertain the extent of the tear.

The Perineal Laceration Registry (PLR) is a section of the Swedish National Quality Register of Gynaecological Surgery ${ }^{(15)}$ that has operated since 1997. The PLR was introduced in 2014 and covers data from 36 of 45 delivery clinics in Sweden in 2018. Most delivery clinics report degree 3 and 4 lacerations to the PLR, while some clinics have chosen to also include women with a seconddegree laceration. The PLR provides data for national comparisons and research ${ }^{(16)}$. The register uses data extracted from medical and obstetric records, such as obstetric characteristics and surgical methodological data.

In this study, demographic and obstetrical data were collected from all primiparous women with an anal sphincter injury registered in the PLR between January 2014 and September 2018. The study population was restricted to primiparous women in order to avoid influence of previous deliveries on the pelvic floor anatomy.

Maternal characteristics extracted were age, body mass index (BMI, measured upon enrolment at the antenatal care center), dyspareunia or genital discomfort before pregnancy, prevalence of inflammatory bowel disease (Crohn's disease or ulcerative colitis) or diabetes mellitus. These parameters were chosen as they are known risk factors or factors of importance for obstetric anal sphincter injury (OASI). 
Obstetric outcome variables extracted were induction of labour, analgesia during delivery (none/infiltration/paracervical/ pudendal/epidural/spinal block), time of pushing, foetal presentation (crown, occiput posterior, breech or other), instrumental delivery (vacuum extraction/forceps), episiotomy, whether the infant was born with an arm beside the head, and birth weight. Available data in the PLR on diagnostic methods include the palpable perineal thickness ${ }^{(17)}$ and the use of ultrasound for evaluating the perineum. The outcome of the diagnostic method of bidigital palpation with one finger in the anal canal and the other in the deepest part of the vaginal laceration to determine the shortest the distance between the fingers, i.e. the perineal palpated thickness, is formalized in the PLR. The distance was classified into three groups (less than $10 \mathrm{~mm}, 10-20 \mathrm{~mm}$ and more than $20 \mathrm{~mm})^{(18)}$. The extent of the perineal laceration (figure 1) was also extracted.

\section{Statistics}

Data were analyzed using SPSS Version 24. Descriptive statistics were presented as mean score and standard deviation (SD). A p-value less than 0.05 was considered as statistically significant. Maternal characteristics were investigated using Pearson's chi-square test for categorical variables and t-tests for numerical variables. Obstetric variables were entered in binary logistic regression analyzes. Reference categories for the analyzes were chosen as follows: spontaneous delivery start, no infiltration anesthesia/ PCB/spinal/pudendal anesthesia/epidural anesthesia, no episiotomy, palpable thickness $>20 \mathrm{~mm}$, perineal laceration degree 3 . Odds ratios (OR) were calculated with 95\% confidence intervals (CI). All analyzes were two-sided.

\section{Results}

The study population consisted of 3,333 primiparous women with a vaginal delivery, a perineal laceration of degree 3 or 4 , and a documented status of the IAS postpartum found in the PLR (fig 2). The study population was further divided into women with an isolated EAS injury and with both an external and internal anal sphincter injury. 1,097 women (32.9\% 1,097/3,333) among all women 
with an EAS injury, and with the IAS evaluated, also had an IAS injury. Among all primiparous women with a third- or fourth-degree perineal laceration, 3,333 of 6,000 had available information in the registry on the status of the IAS, and in 1,097 women the IAS was injured. Of all reported OASIs in the PLR, this corresponds to $18.3 \%(1,097 / 6,000)$ with IAS injury. The distribution of the degree of perineal laceration and the relative contribution of each group to the rate of IAS injury is shown in table 1 .

\section{Maternal characteristics}

The median BMI was $23.4 \mathrm{~kg} / \mathrm{m}^{2}$ (mean 24.4, SD 4.51, range 15.9- 49.8). In this population, 257 had genital discomfort before pregnancy, 32 had inflammatory bowel disease (Crohn's disease or ulcerative colitis) and 28 had diabetes mellitus. There were no significant differences between groups considering maternal characteristics. The results are presented in table 2.

\section{Obstetric characteristics}

The mean infant weight was 3,689 g (SD 480g). Considering induction of labour, chosen analgesic method, foetal presentation (occiput anterior or posterior, breech or other presentation), time of pushing, mode of delivery (spontaneous or instrumental), birth weight and episiotomy, no significant differences were seen. According to the binary logistic regression analysis, the occurrence of the infant's hand beside the head at delivery (OR 1.65, 95\% CI 1.13-2.40) was found to be an independent risk factor for an IAS injury. The results of the obstetric variables are shown in table 3 .

Postpartum, a palpable perineal thickness of less than $10 \mathrm{~mm}$ between the bottom of the laceration and the anorectal mucosa (OR 1.46, 95\% CI 1.08-1.97) is an independent diagnostic sign for IAS injury, as is diagnosing a degree 4 laceration with rupture of the anorectal mucosa (OR 5.93, 95\% CI 4.48-7.85) (table 4).

\section{Comment}

In $33 \%$ of primiparous women with an EAS injury, an IAS injury was diagnosed immediately after delivery. When the infant was born with a hand or arm beside the head, there was an almost two- 
fold increased risk for IAS injury. Risk factors associated with EAS injury, including birth weight, instrumental delivery and occiput posterior presentation, could not be confirmed as independent risk factors for IAS injury. Concerning diagnostic methods in the immediate postpartum period, a perineal palpatory thickness of less than $10 \mathrm{~mm}$ was significantly associated with an IAS injury when compared with a palpatory thickness of $20 \mathrm{~mm}$ or more.

This is to our knowledge the largest population-based cohort study restricted to primiparous women with OASI immediately after delivery, evaluating the proportion, risk factors and diagnostic methods of IAS injury.

The finding in the present study that one third of women with OASI also have an IAS injury, diagnosed immediately postpartum, has not been described before. The prevalence at later stages postpartum has been evaluated with varying results depending on study population, time since delivery and diagnostic methods. Ozyurt et al. ${ }^{(19)}$ studied 201 primiparous women with transperineal ultrasound before hospital discharge after delivery. Seven women had an OASI and two had an IAS injury (28\%). In a study by Mahony ${ }^{(11)}, 500$ women with a diagnosis of OASI were examined with endoanal ultrasound three months after childbirth, and 56.6\% had an IAS injury. Roos et al. ${ }^{(20)}$ showed that $8 \%$ of women with OASI had been diagnosed with an IAS injury at the time of the primary repair. In that study, $27 \%$ of the women had an IAS injury that was found with an endoanal ultrasound nine weeks after delivery but that had not been found in the delivery setting. The different rates in these studies of persistent, undetected IAS injury probably reflect low awareness and diagnostic abilities in the primary settings.

In absolute numbers, most IAS injuries were found in women with incomplete EAS injury. This emphasizes the need for a thorough examination of the perineum even with less extensive perineal lacerations.

The risk factors for OASI have been well described ${ }^{(4,5)}$. In the present study, they were evaluated in relation to IAS injury. There was no independent association between the known OASI risk factors and IAS injury. However, the finding that the infant was born with a hand beside the head 
was identified as a new risk factor. In these cases, the circumference of the presenting part is increased. This suggests that the mechanism for IAS injury might differ from the isolated EAS injury. One might speculate upon whether this is due to a more focused tearing force caused by the hand. The position of the infant's extremities is neither known before birth, nor possible to correct during delivery. The significance of this finding is that it is a warning sign for IAS injury when examining obstetric perineal lacerations.

No anesthetic methods evaluated in the present study were shown as risk factors for IAS injury. In prior studies evaluating major tears $(3 c$ and 4$)$ in later stages postpartum ${ }^{(20)}$, epidural anesthesia was considered a risk factor, but this could not be confirmed concerning IAS injury (3c) in our population.

The design of the PLR made it possible to evaluate diagnostic methods of OASI. In an earlier clinical study we showed that the measurement of palpated perineal thickness was associated with the finding of an EAS injury ${ }^{(18)}$. In the present study we showed that a perineal thickness of less than ten $\mathrm{mm}$ increased the probability of an IAS injury by $50 \%$. The tissue between the vagina and the anal canal is composed of the anal sphincters and the perineal connective tissue. When the structures are torn or missing, the thickness is diminished. This simple diagnostic method with obligatory and documented quantitative palpation can be used to evaluate perineal lacerations in the acute phase immediately after delivery. A palpable thickness of less than ten mm warrants further examination of the sphincter complex.

The documented use of ultrasound for evaluating the perineum in the acute phase is sparse in the PLR $(75 / 3,333,2.2 \%)$ and cannot yet be evaluated in relation to IAS injury due to relatively small numbers. However, transperineal ultrasound measuring the anovaginal distance has been shown to be a promising diagnostic method for examining obstetric perineal lacerations ${ }^{(18)}$. According to ICD, a degree 4 laceration is defined as an injury of the perineum involving the anal sphincter complex (both EAS and IAS) and anal epithelium. Surprisingly, in the present data set, there were a number of lacerations classified as degree 4 despite also registering an intact IAS 
(28\%). There are various possible explanations for this finding. Some lacerations classified as a fourth-degree tear may in fact be an injury of the EAS. The misunderstanding may lie in differentiating between an injury of the anal epithelium above the dentate line (fourth degree) and an injury of the anal skin up to the dentate line. An intact IAS in a true fourth degree laceration that stretches above the dentate line is anatomically unlikely.

A strength of this study is that the PLR is population-based and includes a large number of primiparous women with OASI, which gives sufficient power to evaluate putative risk factors and the efficacy of diagnostic methods according to EAS alone or EAS and IAS. The wide range of maternal and obstetric data in the PLR made it possible to evaluate associations between IAS and maternal and delivery characteristics. The population is unselected, which enhances the generalizability of the present study to similar settings.

General limitations of large register studies are the risk of errors in recorded data, missing values and that only available data can be analyzed. The PLR started in 2014, and has initial registry losses, due to lack of clinical and administrative routines at the clinics and different starting updates. Women for whom decisive information, such as IAS status, were missing, were excluded from further evaluations. The proportion of IAS in women with EAS should be interpreted with caution since it is possible that there are undetected IAS in the group where there is no mark whether the IAS was evaluated or not. Concerning maternal and obstetric risk factors there is no reason to suspect a variation in reporting of those in relation to whether the IAS was evaluated or not. Studying delivery procedures in a nationwide range of clinics, variations of clinical routines and traditions are inevitable. When diagnosing perineal lacerations, where international and often national guidelines are lacking, the diagnostic accuracy of the examiners might vary. The findings from the PLR are reported back to all clinics and an improvement of data coverage is seen with every year.

The methodological and administrative method alternatives are however unlikely to vary in relation to exposure data. 


\section{Conclusions}

Our main finding was that $33 \%$ of the women with an EAS injury also had an IAS injury. If the infant was born with a hand or arm beside the head the risk of an IAS injury was doubled.

Concerning diagnostic methods, a palpable perineal thickness of less than ten mm between the bottom of the laceration and the anorectal mucosa was strongly associated with an IAS. Palpation of perineal thickness is a simple and accessible method that might increase the detection rate of IAS injuries.

Future studies will indicate whether women in the PLR with immediately detected and repaired IAS injuries have different long term outcome compared to women with isolated EAS injuries.

Acknowledgements: None 


\section{References}

1. Organization WH. International Classification of Disease 2015 [Available from: http://www.who.int/classifications/icd/en/.

2. Fornell EK, Berg G, Hallbook O, Matthiesen LS, Sjodahl R. Clinical consequences of anal sphincter rupture during vaginal delivery. Journal of the American College of Surgeons. 1996;183(6):553-8.

3. Sultan AH. Editorial: Obstetrical Perineal Injury and Anal Incontinence. AVMA Medical \& Legal Journal. 1999;5(6):193-6.

4. Andrews V, Sultan AH, Thakar R, Jones PW. Risk factors for obstetric anal sphincter injury: a prospective study. Birth. 2006;33(2):117-22.

5. Dudding TC, Vaizey CJ, Kamm MA. Obstetric anal sphincter injury: incidence, risk factors, and management. Annals of surgery. 2008;247(2):224-37.

6. Fornell EU, Matthiesen L, Sjodahl R, Berg G. Obstetric anal sphincter injury ten years after: subjective and objective long term effects. BJOG : an international journal of obstetrics and gynaecology. 2005;112(3):312-6.

7. Kumar L, Emmanuel A. Internal anal sphincter: Clinical perspective. Surgeon. 2017;15(4):211-26.

8. Sultan AH, Monga AK, Kumar D, Stanton SL. Primary repair of obstetric anal sphincter rupture using the overlap technique. British journal of obstetrics and gynaecology. 1999;106(4):318-23.

9. Rothbarth J, Bemelman WA, Meijerink WJ, Stiggelbout AM, Zwinderman AH, BuyzeWesterweel ME, et al. What is the impact of fecal incontinence on quality of life? Diseases of the colon and rectum. 2001;44(1):67-71.

10. Kuismanen K, Nieminen K, Karjalainen K, Lehto K, Uotila J. Outcomes of primary anal sphincter repair after obstetric injury and evaluation of a novel three-choice assessment. Techniques in coloproctology. 2018;22(3):209-14.

11. Mahony R, Behan M, Daly L, Kirwan C, O'Herlihy C, O'Connell PR. Internal anal sphincter defect influences continence outcome following obstetric anal sphincter injury. Am J Obstet Gynecol. 2007;196(3):217 e1-5.

12. Andrews V, Sultan AH, Thakar R, Jones PW. Occult anal sphincter injuries--myth or reality? BJOG : an international journal of obstetrics and gynaecology. 2006;113(2):195-200.

13. Frudinger A, Ballon M, Taylor SA, Halligan S. The natural history of clinically unrecognized anal sphincter tears over 10 years after first vaginal delivery. Obstet Gynecol. 2008;111(5):1058-64.

14. Norderval S, Oian P, Revhaug A, Vonen B. Anal incontinence after obstetric sphincter tears: outcome of anatomic primary repairs. Diseases of the colon and rectum. 2005;48(5):1055-61.

15. Gynop.se/home 2019 [2019-02-27]. Available from: www2.gynop.se/home.

16. Lindqvist M, Persson M, Nilsson M, Uustal E, Lindberg I. 'A worse nightmare than expected' - a Swedish qualitative study of women's experiences two months after obstetric anal sphincter muscle injury. Midwifery. 2018;61:22-8.

17. Zetterstrom JP, Mellgren A, Madoff RD, Kim DG, Wong WD. Perineal body measurement improves evaluation of anterior sphincter lesions during endoanal ultrasonography. Diseases of the colon and rectum. 1998;41(6):705-13.

18. Pihl S, Uustal E, Blomberg M. Anovaginal distance and obstetric anal sphincter injury: a prospective observational study. Int Urogynecol J. 2018.

19. Ozyurt S, Aksoy H, Gedikbasi A, Yildirim G, Aksoy U, Acmaz G, et al. Screening occult anal sphincter injuries in primigravid women after vaginal delivery with transperineal use of vaginal probe: a prospective, randomized controlled trial. Archives of gynecology and obstetrics.

2015;292(4):853-9.

20. Roos AM, Thakar R, Sultan AH. Outcome of primary repair of obstetric anal sphincter injuries (OASIS): does the grade of tear matter? Ultrasound Obstet Gynecol. 2010;36(3):368-74. 
Figure Caption List

Figure 1. Classification of perineal lacerations. EAS - External Anal Sphincter. IAS - Internal Anal Sphincter.

Figure 2. Flow Chart Inclusion 
Figure 1. Classification of perineal lacerations. EAS - External Anal Sphincter. IAS - Internal Anal Sphincter.

\begin{tabular}{|c|c|}
\hline Type of tear & Definition \\
\hline First degree tear & Injury to perineal skin \\
\hline tear & Injury to perineum involving perineal muscles but not involving \\
\hline third degree tear & Injury to the perineum involving the anal sphincter complex \\
\hline $3 \mathrm{~A}$ & Less than 50\% of EAS thickness torn \\
\hline $3 \mathrm{~B}$ & More than 50\% of EAS thickness torn \\
\hline 3C & Both EAS and IAS torn \\
\hline Fourth degree tear & Injury to perineum involving the anal sphincter complex (both \\
& EAS and IAS) and anal epithelium \\
\hline
\end{tabular}




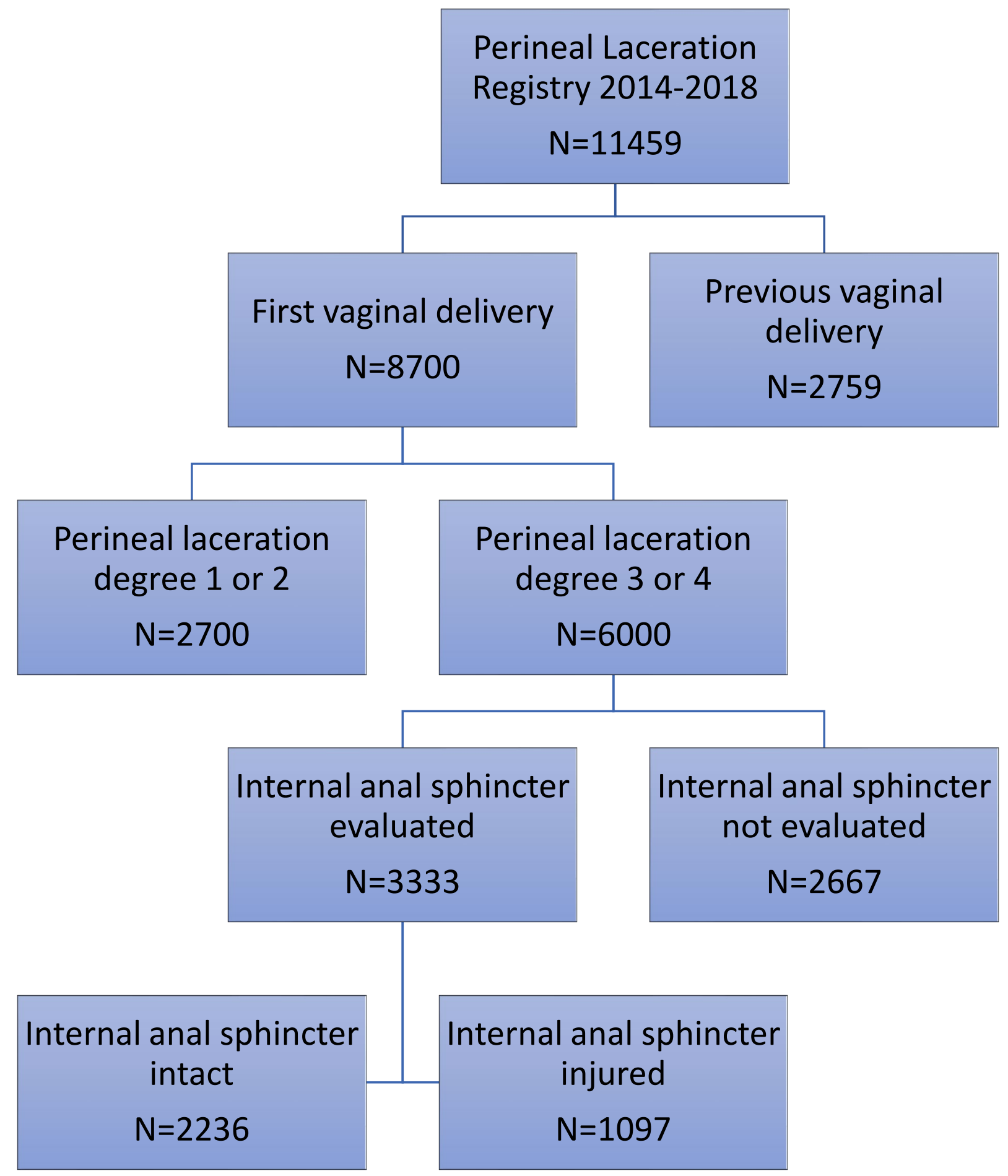


Table 1. The proportion of internal sphincter injury depending on the extent of external anal sphincter injury.

\begin{tabular}{|c|c|c|c|c|c|}
\hline $\begin{array}{c}\text { Internal sphincter } \\
\text { injury }\end{array}$ & $\begin{array}{c}\text { Less than } 50 \% \text { of } \\
\text { EAS thickness } \\
\text { torn } \\
\mathrm{N}=1580\end{array}$ & $\begin{array}{c}\text { More than } 50 \% \text { of } \\
\text { EAS thickness } \\
\text { torn } \\
\mathrm{N}=769\end{array}$ & $\begin{array}{c}100 \% \text { of EAS } \\
\text { thickness torn } \\
\mathrm{N}=611\end{array}$ & $\begin{array}{c}\text { Fourth degree tear } \\
\mathrm{N}=267\end{array}$ & Total \\
\hline $\begin{array}{c}\text { Internal } \\
\text { sphincter injury }\end{array}$ & $345(21.8)$ & $174(22.6)$ & $255(41.7)$ & $190(71.2)$ & 964 \\
$\mathrm{~N}$ (\%) & & & & \\
\hline $\begin{array}{c}\text { Relative } \\
\text { contribution of } \\
\text { group to overall } \\
\text { IAS injury rate } \\
\text { (\%) }\end{array}$ & 35.8 & 18.0 & 26.5 & 19.7 & \\
\hline
\end{tabular}


Table 2. Maternal characteristics, comparing women with external anal sphincter injury (3A and B) with women with external and internal anal sphincter injury (3C). SD - Standard Deviation.

\begin{tabular}{|c|c|c|c|c|}
\hline Characteristic & $\begin{array}{l}\text { Obstetric anal } \\
\text { sphincter injury } \\
\qquad \mathrm{N}=3333\end{array}$ & $\begin{array}{c}\text { External anal } \\
\text { sphincter injury } \\
\text { (3A and B) } \\
\text { N=2236 (67.1\%) }\end{array}$ & $\begin{array}{l}\text { External and } \\
\text { internal anal } \\
\text { sphincter injury } \\
\text { (3C) } \\
\mathrm{N}=1097(32.9 \%)\end{array}$ & $p$-value \\
\hline Age mean (SD) & $29.68(4.70)$ & $29.77(4.58)$ & $29.49(4.64)$ & 0.08 \\
\hline BMI mean (SD) & $24.42(4.51)$ & $24.31(4.44)$ & $24.63(4.65)$ & 0.06 \\
\hline $\begin{array}{c}\text { Dyspareunia scale* } \\
\text { mean (SD) }\end{array}$ & $2.41(0.82)$ & $2.37(0.74)$ & $2.48(0.94)$ & 1.00 \\
\hline $\begin{array}{l}\text { Genital discomfort } \\
\text { before pregnancy, } \\
\text { N (\%) }\end{array}$ & $257(11)$ & $172(7.3)$ & $85(3.6)$ & 0.31 \\
\hline $\begin{array}{c}\text { Crohn/Ulcerative } \\
\text { Colitis, N (\%) }\end{array}$ & $32(1.0)$ & $22(0.7)$ & $10(0.3)$ & 0.83 \\
\hline Diabetes, N (\%) & $28(0.8)$ & $19(0.6)$ & $9(0.3)$ & 0.84 \\
\hline
\end{tabular}

*Dyspareunia before delivery. Grades $1-5,1=$ no dyspareunia, 5, very strong pain. 


\begin{tabular}{|c|c|c|c|}
\hline Outcome & $\begin{array}{l}\text { Obstetric anal sphincter } \\
\text { injury }(3 \mathrm{~A}, \mathrm{~B}) \\
\mathrm{N}=\mathbf{2 2 3 6}\end{array}$ & $\begin{array}{l}\text { External and internal anal } \\
\text { sphincter injury (3C) } \\
\qquad \mathrm{N}=1097\end{array}$ & OR (95\% Cl) \\
\hline $\begin{array}{c}\text { Induction of labour } \\
\text { n (\%) }\end{array}$ & $499(22.3)$ & $261(23.7)$ & $1.09(0.92-1.29)$ \\
\hline $\begin{array}{c}\text { No anesthesia } \\
\text { n (\%) }\end{array}$ & $269(8.1)$ & $154(14.0)$ & $0.84(0.68-1.04)$ \\
\hline $\begin{array}{l}\text { Infiltration of anesthetics } \\
\qquad \mathrm{n}(\%)\end{array}$ & $343(15.3)$ & $149(13.5)$ & $1.09(0.88-1.34)$ \\
\hline $\begin{array}{c}\text { Paracervical block } \\
\text { n (\%) }\end{array}$ & $8(0.4)$ & $1(0.09)$ & $0.25(0.03-2.03)$ \\
\hline $\begin{array}{l}\text { Pudendal block } \\
\text { n (\%) }\end{array}$ & $215(9.6)$ & $94(8.5)$ & $0.80(0.62-1.03)$ \\
\hline $\begin{array}{c}\text { Spinal anesthesia } \\
\text { n (\%) }\end{array}$ & $28(1.2)$ & $12(1.1)$ & $0.87(0.44-1.72)$ \\
\hline $\begin{array}{c}\text { Epidural anesthesia } \\
\qquad \mathrm{n}(\%)\end{array}$ & $1406(62.9)$ & $691(63.0)$ & $1.01(0.87-1.17)$ \\
\hline $\begin{array}{c}\text { Time of pushing }<30 \mathrm{~min} \\
\mathrm{n}(\%)\end{array}$ & 767 (34.3) & $410(37.3)$ & ref \\
\hline $\begin{array}{l}\text { Time of pushing } 31-60 \mathrm{~min} \\
\qquad \mathrm{n}(\%)\end{array}$ & $844(40.0)$ & $395(36.0)$ & $1.09(0.89-1.33)$ \\
\hline $\begin{array}{c}\text { Time of pushing }>60 \mathrm{~min} \\
\mathrm{n}(\%)\end{array}$ & $499(22.3)$ & $238(21.7)$ & $0.98(0.81-1.19)$ \\
\hline $\begin{array}{l}\text { Occiput anterior } \\
\text { n (\%) }\end{array}$ & $2119(94.8))$ & $1026(93.5)$ & $0.73(0.12-4.35)$ \\
\hline $\begin{array}{l}\text { Occiput posterior } \\
\text { n (\%) }\end{array}$ & $90(4.0)$ & $58(5.2)$ & $0.97(0.16-5.96)$ \\
\hline Breech & $6(0.3)$ & $1(0.1)$ & $0.25(0.16-4.00)$ \\
\hline
\end{tabular}




\begin{tabular}{|c|c|c|c|}
\hline Outcome & $\begin{array}{l}\text { Obstetric anal sphincter } \\
\text { injury }(3 \mathrm{~A}, \mathrm{~B}) \\
\mathrm{N}=2236\end{array}$ & $\begin{array}{l}\text { External and internal anal } \\
\text { sphincter injury (3C) } \\
\qquad N=1097\end{array}$ & OR (95\% Cl) \\
\hline \multicolumn{4}{|l|}{ n (\%) } \\
\hline $\begin{array}{l}\text { Other fetal presentation } \\
\qquad \mathrm{n}(\%)\end{array}$ & $18(0.8)$ & $10(0.9)$ & $0.83(0.12-5.85)$ \\
\hline $\begin{array}{c}\text { Vacuum extraction } \\
\mathrm{n}(\%)\end{array}$ & $632(28.3)$ & $315(28.7)$ & $0.40(0.12-1.33)$ \\
\hline $\begin{array}{l}\text { Forceps } \\
\text { n (\%) }\end{array}$ & $5(0.2)$ & $6(0.5)$ & $0.42(0.13-1.37)$ \\
\hline $\begin{array}{l}\text { Episiotomy } \\
\text { n (\%) }\end{array}$ & $282(12.6)$ & $136(12.3)$ & $1.02(0.82-1.27)$ \\
\hline $\begin{array}{c}\text { Infant born with an arm } \\
\text { by the head } \\
n(\%)\end{array}$ & $68(3.0)$ & $53(4.8)$ & $1.65(1.13-2.40)$ \\
\hline $\begin{array}{c}\text { Birth weight }<3000 \mathrm{~g} \\
\mathrm{n}(\%)\end{array}$ & $129(5.8)$ & $66(6.0)$ & ref \\
\hline $\begin{array}{l}\text { Birth weight } 3001-4000 \mathrm{~g} \\
\mathrm{n}(\%)\end{array}$ & $1372(61.3)$ & $657(59.9)$ & $1.08(0.77-1.51)$ \\
\hline $\begin{array}{c}\text { Birth weight }>4000 \mathrm{~g} \\
\mathrm{n}(\%)\end{array}$ & $484(21.6)$ & $229(20.9)$ & $1.01(0.84-1.22)$ \\
\hline
\end{tabular}


Table 4. Outcome or methods for diagnosing perineal laceration comparing women with external anal sphincter injury (3A and B) with women with external and internal anal sphincter injury (3C). OR - Odds Ratio. CI - Confidence Interval.

\begin{tabular}{|c|c|c|c|}
\hline Outcome or diagnostic method & $\begin{array}{l}\text { Obstetric anal } \\
\text { sphincter injury } \\
\qquad \begin{array}{c}\text { (3A, B) } \\
\mathrm{N}=2236\end{array}\end{array}$ & 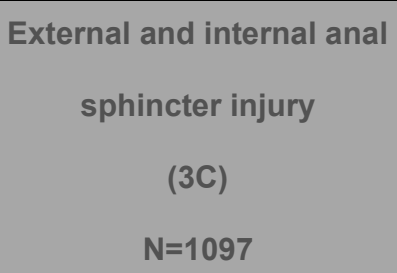 & OR (95\% Cl) \\
\hline $\begin{array}{l}\text { Third degree laceration } \\
\qquad \mathrm{n}(\%)\end{array}$ & $2162(96.7)$ & $912(83.1)$ & ref \\
\hline $\begin{array}{l}\text { Fourth degree laceration } \\
\qquad n(\%)\end{array}$ & $74(3.3)$ & 185 (16.9) & $5.98(4.48-7.85)$ \\
\hline $\begin{array}{l}\text { Palpable perineal thickness }<10 \mathrm{~mm} \\
\qquad \mathrm{n}(\%)\end{array}$ & 780 (34.9) & $425(38.7)$ & $1.28(1.04-1.56)$ \\
\hline $\begin{array}{l}\text { Palpable perineal thickness } 10 \text { - } \\
\qquad \begin{array}{c}20 \mathrm{~mm} \\
n(\%)\end{array}\end{array}$ & 655 (29.3) & 207 (18.9) & $0.87(0.68-1.08)$ \\
\hline $\begin{array}{l}\text { Palpable perineal thickness } \\
\qquad \begin{array}{c}>20 \mathrm{~mm} \\
\mathrm{n}(\%)\end{array}\end{array}$ & $212(9.5)$ & $81(7.4)$ & ref \\
\hline $\begin{array}{l}\text { Transperineal ultrasound } \\
\qquad \mathrm{n}(\%)\end{array}$ & $59(2.6)$ & $16(1.4)$ & $0.62(0.35-1.08)$ \\
\hline
\end{tabular}

